\title{
Self-care profiles of the elderly institutionalized in Elderly Care Centres
}

\author{
Cristina Imaginário ${ }^{\mathrm{a}, \mathrm{b}}$, Magda Rocha ${ }^{\mathrm{b}}$, Paulo Machado ${ }^{c}$, Cristina Antunes ${ }^{\mathrm{a}}$, Teresa Martins $\mathrm{s}^{\mathrm{c}^{*}}$
}

a Universidade de Trás-os-Montes e Alto Douro, Escola Superior de Saúde, Portugal

${ }^{b}$ CINTESIS - Center for Health Technology and Services Research, Portugal

${ }^{\mathrm{c}}$ Escola Superior de Enfermagem do Porto, CINTESIS - Center for Health Technology and Services Research, Portugal

Keywords:

Institutionalized elderly

Self-care

Self-care profiles

\section{A B S T R A C T}

The concept of self-care in the elderly has been frequently associated with autonomy, independence and personal accountability. Self-care practices are a result of individual lifestyles and paths adapted to the circumstances and expectations of the elderly. Based on the model by Backman and Hentinen (1999), the present study attempts to categorically describe the types of self-care of the elderly. This is an exploratory study, transversal, of a quantitative nature. The sample was comprised of $\mathbf{3 1 3}$ participants, randomly selected among Elderly Care Centres in the interior North of Portugal. The Portuguese version of Self-care of Home Dwelling Elderly was used for data collection. The results call for a replication of the study, using the theoretical derivation of the four self-care profiles (responsible, formally guided, independent and abandoned).

\section{Introduction}

The concept of self-care has been commonly associated with levels of autonomy, independence and personal accountability. The definition of self-care includes the performance of free-initiative activities aiming at the preservation of life, health and personal well-being (Orem, 2001), namely health promotion or recovery. Therefore, it is a complex and multidimensional phenomenon (Petronilho, 2012).

This notion of self-care emerges as a means of health promotion performed intentionally and rationally (Backman \& Hentinen, 1999, 2001; Rasanen, Backman, \& Kyngas, 2007; Zeleznik, 2007).

However, self-care should not be considered exclusively from a logical perspective of health promotion, but rather as part of a broader context, which takes into account the importance of self-care with regard to the activities of daily living (ADLs). Thus, self-care practices are the result of individual lifestyles and personal adaptation of the elderly's life history to their circumstances and personal expectations (Backman \& Hentinen, 1999, 2001; Rasanen et al., 2007; Zeleznik, 2007).

The literature suggests that the factors influencing self-care actions can be divided into external and internal factors (Backman \& Hentinen, 1999). The living conditions, the aid services provided to the elderly and the social support are all part of the external factors. The latter combines the emotional, instrumental or educational support con-tributing to the maintenance of autonomy and independence (Backman \& Hentinen, 1999; Rasanen et al., 2007; Wichmam, Couto, Areosa, \&Menéndez Montañes, 2013). Concerning the internal factors, the health condition can be seen as a priori determinant for self-care. There are also other internal factors to be considered, such as functional capacity and health, coping strategies and resilience (Backman \& Hentinen, 1999, 2001; Zeleznik, 2007).

Backman and Hentinen (1999) outlined the construction of a theoretical model explaining the types of self-care found among the homedwelling elderly. Self-care behaviours in the elderly are viewed as actions aimed at maintaining or restoring health, and the performance of their ADLs. The model presents different self-care types with their corresponding conditions in terms of action and associated meanings. Therefore, it is possible to identify four profiles: responsible, formally guided, independent and abandoned.

The responsible self-care implies activity and accountability in all the ADLs, including concern over the health processes. The elderly with this profile control the management of their own treatment regimen, understand the assumptions for the suggested therapies and want to make informed decisions about alternative therapies. Once they perceive any health problems, they take an active attitude, seeking appropriate help immediately and without hesitation. They want to be informed about the conditions and symptoms presented, as well as the different treatment options. Therefore, they actively collaborate with health care professionals, often establishing long-life relationships. These elderly people adopt healthy daily lifestyle habits, taking care of their physical condition, either as part of a healthy diet, or in their exercise routines. For these elderly people, the performance of daily activities is a positive accomplishment. The positive, future-oriented attitude and the positive experience of ageing are important pre-requisites to the responsible self-care profile. These people value their professional activity and after retirement, they finally have the opportunity to engage in different projects involving tasks and activities they wish to experience. They devote time to themselves, realizing that the hard work has given way to the enjoyment of everyday living. Therefore, ageing means a new kind of living. Being responsible is to wish to continue living actively, enjoy social activities, have positive relationships with family and friends, trust and hope in the future, and also to expect the support of others if and when it is necessary.

The formally guided profile consists of regular compliance, but an uncritical attitude towards the therapeutic counselling, involving simple routines with no satisfaction involved in the performance of daily tasks. This profile is often associated with people who have experienced a life history based on the dependency of others. It concerns people who left the nuclear family early to start a professional activity, frequently reporting a life cycle characterized by hard work. They do not recognize their own personal needs and perceive ageing only as an inevitable decline of physical and cognitive skills. These people face the course of their life cycle with the cognitive bias of inevitability and accept their increasing decline. Ageing is associated with retirement and therefore they accept limitations in the ADLs. Despite their wish to remain in their own houses, they are conscious of the potential need for future institutionalization.

The elderly with an independent self-care profile tend to manage their health-disease processes by questioning the therapeutic 
recommendations of health professionals. They find original ways to take care of themselves and when they perceive any problems associated with their health or well-being, they do not seek the help of health professionals. These people try to find answers to their problems by themselves, based on their life cycle experiences and personal beliefs. This type of profile is grounded on "the school of life" philosophy. It is based on a strict view of managing their personal lives, often characterized by stories of personal determination in relation to their lives, professional activity and social relationships. People in this profile usually deny the ageing process and tend to hide disease signs and symptoms. They often compare themselves to other elderly people, by emphasizing that they are healthier and do not need medication. They expect to remain in their own houses because it gives them a sense of safety and they tend to prefer being alone, while undermining the importance of their social network.

Lastly, the abandoned self-care profile is characterized by personal representations of helplessness and lack of accountability. These elderly people do not care for themselves and are unable to manage the ADLs. This sense of helplessness and incapacity is multidimensional, often revealed by the desire to give up on life. This self-care profile is commonly characterized by reports of life stories embedded in bitterness and sadness. They tend to be introverts and their past and current lives are characterized by poverty, lack of respect or understanding from significant others or third parties. The feeling of bitterness often seems to be based on the perception of negative experiences throughout life, including reports of hard work, unsatisfactory marital relations or episodes of violence, or experiences and recall of traumatic events. They have a negative attitude towards the ageing process, with personal representations of the life cycle involving pain (physical and/or psychological) and incapacity, resulting in feelings of helplessness, loneliness and abandonment. This profile is characterized by a desire to give up and entails a feeling of loss of control of their personal life, due to their perception of personal physical and mental decline and to a low or non-existent social support. Concerning the future, the fear of pain is constantly present, as well as the decline of functional capacities, the continued loss of personal control over their lives and the fear of death itself. Rasanen et al. (2007) developed a self-report instrument to evaluate self-care in the elderly, living either in care institution or in clinical contexts. The instrument presents five independent scales, in which the behaviours in self-care, self-care guidance, functional capacity in the basic activities of daily living (BADLs) and in the instrumental activities of daily living (IADLs), satisfaction with life and self-esteem. Based on this model, Backman and Hentinen (1999), designed a scale with 42 items to assess self-care profiles.

The present study sought to describe categorically the self-care profiles of a random sample of institutionalized elderly, using the Backman and Hentinen (1999) and analysing the theoretical derivation of the identified profiles.

\section{Methods}

This is an exploratory, cross-sectional study, of a quantitative nature. The research is non-experimental or Ex Post Facto. Preliminary analyses to establish the correct number of clusters or profiles were performed using the Latent Profile Analysis approach (LPA). A multi- variate data analysis was then performed, through a clusters' analysis by means of the combinatory procedure (Hair, Black, Babin, \& Anderson, 2010).

This study was approved by the ethical committee of Abel Salazar Institute of Biomedical Sciences, under the registration number $166 /$ 2016.

The data was collected and processed only by the main researcher, in a single moment with each respondent in a reserved room. All ethical principles, anonymity and confidentiality were assured. The participants were asked to sign an informed consent form after being provided with all the information concerning the researcher, the nature of the research and its objectives. Given the age and educational limitations of the participants, the questionnaires were administered orally by the person in charge of this study.

\subsection{Participants}

Participants were recruited from the 56 Elderly Care Centres (ECC) located in the interior north of Portugal (in the Vila Real district and in each municipality), registered as Private Institutions of Social Solidarity. Only the institutions that gave written permission to participate in the study and that were willing to integrate the sample were included. Data collection took place between August 2014 and July 2015 . Prior to this process, the people responsible for each institution were informed of the protocol to be used. A total of 25 ECC accepted to participate in the study. Participants were recruited from these $25 \mathrm{ECC}$, through a simple random procedure. Each elderly person was assigned a number on a card, placed in a bag and $30 \%$ of the total number of residents of each ECC were selected (Field, 2009; Fortin, 2003). If the selected elderly person refused to participate, another card was selected. Participants without the cognitive capacity to give consent were also included after their families' consent. In these cases, only the physical assessment was performed.

\subsection{Instruments}

The Self-care of Home Dwelling Elderly (SCHDE, Backman \& Hentinen, 1999, 2001; Rasanen et al., 2007) was applied. This instrument is a part of a larger protocol that includes a total of five evaluation instruments (Self-care orientation; Self-esteem; Life satisfaction; Functional capacity (Personal activities of daily living and Instrumental activities of daily living) and Types of self-care. All these instruments were already translated and adapted to the Portuguese population, with several psychometric studies already performed.

The SCHDE was not fully applied, since the main goal of the re-searcher was to categorically describe the four main types of self-care of the studied sample. So, the SCHDE Types of Self-Care Scale (TSCS; Rasanen et al., 2007), included 42 items of the self-report, with a five- point Likert scale (from $1=$ Total Disagree to $5=$ Total Agree). The

Portuguese version of the scale (Sequeira, 2011) is divided into four subscales, namely, the responsible self-care profile (13 items), the for- mally guided self-care profile (10 items), the independent self-care profile (12 items) and, the abandoned self-care profile ( 7 items). The factorial structure was tested taking into consideration the requirements suggested by Rasanen et al. (2007) for the exploratory factor analysis (withdrawing items loading under 0.35, eigenvalues greater than one and the scree plot observation). The items that saturated in more than one factor were excluded if the difference between them was equal or lower than 0.100 . Three solutions were tested: 8 (as the original one), 5 and a 4 factorial one (according to the scree plot). The EFAs were performed using the principal components extraction method and by rotating the matrix (Varimax solution with Kaiser normalization). The latter solution was the one that best approached the theoretical model, despite one 
factor being excluded, which presented a low internal consistency value, either using the Cronbach's alpha $(\alpha=0.48)$ or the average inter-item correlation value $\left(r_{A l l}=0.14\right)$ for short scales, with a cutoff value between 0.15 and 0.50 (Clark \& Watson, 1995). The syntactic consistency of items was also observed, and two items were excluded (22 and 17) from the factors 1 and 2 respectively, since they did not fit the overall model (these items did not lower the Cronbach alpha value at low internal consistency values). Therefore, the factorial structure used in this study consisted of three factors. The first one was named Health representations ( 10 items; $\left.\alpha=0.74 ; r_{A l l}=0.22\right)$; the second with 6 items $(\alpha=0.74$; $\left.r_{A l l}=0.32\right)$ named Autonomous perspectives (which includes medication issues), and finally the third factor Demands associated with personal life (4 items, $\alpha=0.66 ; r_{A l l}=0.33$ ). The latter were then added and averaged to create the three main scale dimensions that would later be transformed, by means of a combinatory cluster analysis (Hair et al., 2010), into categorical data. A sociodemographic questionnaire was also used, specially designed for sample description purposes.

\subsection{Statistical methods}

Before constructing the clusters, preliminary analyses were per-formed using the Latent Profile Analysis (LPA) to establish the most correct solution for the constraints used in the statistical model and to further analyze the range of classes to be tested. The solution to com-pare profiles, the Bayesian Information Criteria (BIC), was the criterion to choose the constraining option and the range of profiles' to be analyzed (following the BIC lowest value principle). The range of classes were tested using the estimation of profiles procedure (finite mixture modelling). The model for the follow-up analyses was established by comparing the models' log-likelihood value, the BIC, and the Entropy value. Using these three assessment criteria is considered a good practice, especially when the comparison is between non-nested models (Tein, Coxe, \& Cham, 2014, p. 643). After the number of profiles solution was established, preliminary analyses for checking the assumptions of the multivariate analysis of data were performed (normality of distribution and outliers' existence).

Combinatory cluster analysis is a statistical procedure that combines hierarchical benefits to describe the centroids and identify possible outliers. As the non-hierarchical methods are less susceptible to outliers, the data are then grouped using non-random seeds. The dimensions of selfcare types are transformed into $z$ scores. The values of the centroids [four groups because the number of clusters is determined aprioristically, since it is used the SCHDE Types of Self-Care model (Backman \& Hentinen, 1999, 2001; Rasanen et al., 2007)] are then calculated by means of the hierarchical method (Ward's method and Square Euclidean Distance). The latter average of each group (seeds) will then be used in the computation of the final clusters by applying the latter non-hierarchical method (K-means). The last statistical step of the procedure is the validation of the remaining categorical variable by performing univariate analysis of variance (ANOVA), where the three scalar dimensions are the dependent variables and the categorical variable, the independent variable. Finally, considering both the features of each group in terms of the averages obtained for each of the three dimensions, as well as the underlying theoretical model, the groups are carefully characterized, derived and validated from a theo- retical point of view. All the statistical procedures are performed using IBM ${ }^{\circ}$ 's SPSS (version 22), except for the Latent Profile Analysis, which used the RStudio software (RStudio Team, 2015) by means of the tidy LPA package (Rosenberg, Schmidt, Beymer, \& Steingut, 2018).

Following this statistical procedure, the descriptive data will be presented and argued considering the model of self-care of homedwelling elderly (Backman \& Hentinen, 1999, 2001; Rasanen et al., 2007) and its usefulness to the Portuguese context of nursing care provided to the elderly populations.

\section{Results}

\subsection{Participants}

A total of 475 elderly people participated in this study, although only the data without missing values were considered in order to avoid any measurement biases by replacing missing values with averages calculations ( $N=313,201$ women, 112 men, $M_{\text {age }}=83.44, S D=7.12$, age range $=65-104)$. Approximately $50 \%$ of the participants were il- literate $(n=150,47.90 \%)$, and another $50 \%$ had completed the basic primary cycle of education (between 1 and 4 years of schooling, $n=148,48.40 \%$ ). The remaining 14 elderly people had between 5 and 11 years of schooling $(4.40 \%)$. The PORDATA (FFMS, 2017) data base suggests that in Portugal the illiterate population stems mainly from the elderly group (65 or older). Although some of the individuals in the sample had one or two years of schooling, in fact they are functionally illiterate. The sample consisted mostly of widowers $(n=188,60.10 \%)$, with the remaining participants living in marital or nonmarital status $(n=54,17.30 \%)$, single $(n=65$, $20.80 \%)$ and only 6 being divorced (1.90\%).

\subsection{Preliminary analyses}

The LPA analysis indicated that the lowest BIC was found for the model with no constraints for means and variances, and in which the covariances were fixed to zero. Two models with four and five classes were tested using the latter (see Fig. 1. below).

The results of the estimation of profiles indicated that the model with four classes had the best fit $(\log \mathrm{L}=1109.29, \mathrm{BIC}=2373.727, \mathrm{H}=$ $0.89)$, in comparison with the five classes model $(\log \mathrm{L}=1078.282, \mathrm{BIC}=2351.934, \mathrm{H}=0.87)$. Although the $\mathrm{BIC}$ is lower for the latter, the other two fit indicators proved a better fit in the four classes model. 
The normal distribution of data was confirmed by calculating Kurtosis and Skewness values, using the cutoff values between +2 and -2 suggested by George and Mallery (2010) $\left(k\right.$ urt $_{(\mathrm{x})}$ between 0.28 and -1.45 ; skew ${ }_{(\mathrm{x})}$ between $\left.-0.33-1.63\right)$. A multivariate analysis of outliers was computed, using the Mahalanobis distance with a significant value of $p<.001$. Data was all computed, since only three values were considered as outliers $(p<.001)$. The analysis of the SCHDE Types of Self-care Scales showed good internal consistency, although the exploratory factor analysis did not replicate the original eight factors structure (Rasanen et al., 2007), nor the twelve-factor obtained by Zeleznik (2007). The Portuguese studies accessed, all presented low Cronbach alphas values (David, 2015; Evaristo, 2012; Mota, 2011; Rodrigues, 2011; Sequeira, 2011, Veríssimo, 2013).

\subsection{Cluster analysis using the combinatory method}

The combinatory clusters analysis method was used to define if the data obtained by means of the dimensions of the SCHDE Types of Self- Care Scale could be structured into the four pure styles described by the authors, sorting the similar data into groups. At first, the 3 dimensions

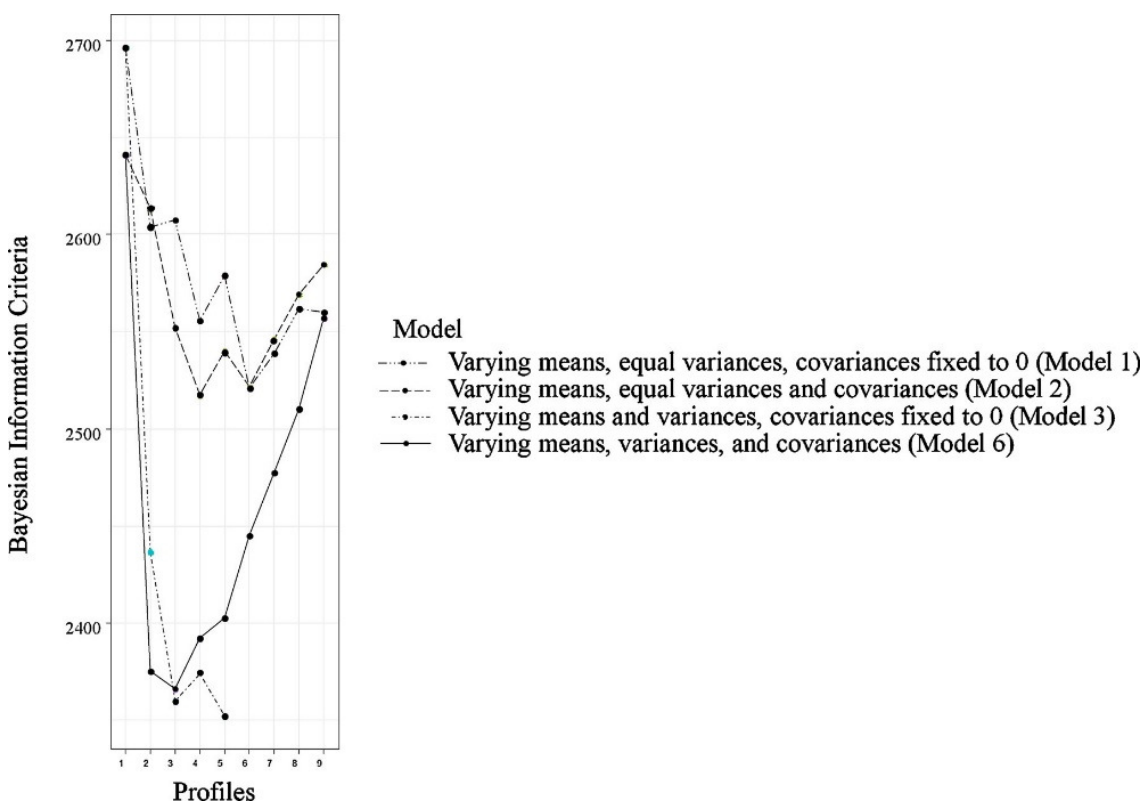

Fig. 1. Results for choosing the number of classes to be tested for establishing the latter SCHDE Types of Self-Care Clusters

Table 1

Hierarchical Centroids (Ward's Method and Squared Euclidean Distance).

Clusters Types of Self-Care Scale Dimensions' z scores

\begin{tabular}{llll}
\cline { 3 - 4 } & $\begin{array}{l}\text { Health } \\
\text { representation }\end{array}$ & $\begin{array}{l}\text { Autonomous } \\
\text { perspectives }\end{array}$ & $\begin{array}{l}\text { Demands } \\
\text { associated with }\end{array}$ \\
\hline 1 & -0.59701 & -0.61836 & 0.47879 \\
2 & 1.63528 & 0.47607 & 0.15315 \\
3 & 0.10760 & 0.02881 & -1.63438 \\
4 & 0.00465 & 1.18433 & 0.46471
\end{tabular}

Note. Hierarchical centroids that will be used as seeds for constructing the last clusters by means of the K-means non-hierarchical method.
Table 2

Final Non-hierarchical Centres (K-means), Clusters and Effective by Group ( $\mathrm{n}$ ).

Clusters Types of Self-Care Scale Dimensions' z scores

\begin{tabular}{lllll}
\cline { 3 - 4 } & & Health & Autonomous & Demands \\
\hline & & representation & perspectives & associated with \\
\hline & $\mathrm{n}$ & & & \\
2 & 138 & -0.66063 & -0.78551 & 0.37722 \\
3 & 55 & 1.55961 & 0.53179 & -0.03295 \\
4 & 45 & 0.14226 & 0.11597 & -1.91858 \\
& 75 & -0.01352 & 0.98578 & 0.48123 \\
$\mathrm{~N}$ & 313 & & & \\
& & & &
\end{tabular}

Note. Final non-hierarchical centres arising from the application of K-means to the previously calculated hierarchical centroids.

were transformed into $z$ scores. Specifying at the outset the existence of the four theoretically pure groups, by means the of the Squared Euclidian Distance, the similarity between data was obtained, by applying Ward's Methods to the z scores to construct the hierarchical clustering centroids, minimizing internal variation (see Table 1 below).

Then, the final clusters were constructed using the hierarchical centroids but by means of non-hierarchical K-means method. This procedure allows to enhance the results, given that non-hierarchical methods are likely less susceptible to evidence outliers and to the introduction of inappropriate variables, enabling to change the pertinence to groups (adapt. Hair et al., 2010, pp. 403). Table 2 summarizes the results for final clusters centres using the K-means method. 


\subsection{Statistical derivation}

The statistical validation of the identified clusters was performed by means of three General Linear Model Univariate Analysis of Variance (ANOVA), using the TSCS dimensions as dependent variables and the nominal clusters as the independent variable. Tests between subjects' effects in all the three TSCS dimensions were significant and were followed by Post Hoc Tests (multiple comparisons using the Scheffé Test, $p \leq .05$ ). For Health representations ANOVA the results were $\left[F(3,309)=171.51, p<.001 ; \eta_{p}{ }^{2}=0.63\right.$, Observed power of 1.00]. The Post-Hoc Tests (Sheffé) indicated significant differences between all groups, except for the differences between groups 3 and 4. Tests be- tween subjects' effects for the Autonomous perspectives $\left[F(3,309)=130.19, p<.001 ; \eta_{p}{ }^{2}=056\right.$, Observed power of 1.00$]$, al- lowed multiple comparisons. In this case, all clusters differ significantly from each other. Finally, the results of significant tests of between- subjects' effects for Demands associated with personal life were $\left[F(3,309)=191.04, p<.001 ; \eta_{p}{ }^{2}=065\right.$, Observed power of 1.00]. The Post Hoc Tests indicated that cluster 4 did not diverge significantly from cluster 1 , but all other groups differed significantly from each other. The ANOVA results are presented in Table 3.

Table 3

Types of Self-Care Scale Clusters Means, Standard Deviations, Confidence Interval and Partial Effectives.

\begin{tabular}{|c|c|c|c|c|c|c|c|c|c|c|c|c|}
\hline \multirow{3}{*}{ TSCD } & \multicolumn{12}{|c|}{ SCHDE Types of Self-Care Clusters } \\
\hline & \multicolumn{2}{|l|}{1} & \multirow[b]{2}{*}{$\mathrm{M}_{\mathrm{Cl}}$} & \multicolumn{3}{|l|}{2} & \multirow{2}{*}{$\begin{array}{l}3 \\
M \\
(n=45)\end{array}$} & & & \multirow{2}{*}{$\begin{array}{l}4 \\
M \\
(n=75)\end{array}$} & \multirow[b]{2}{*}{ SD } & \multirow[b]{2}{*}{$\mathrm{M}_{\mathrm{Cl}}$} \\
\hline & $\begin{array}{l}M \\
(n=138)\end{array}$ & SD & & $\begin{array}{l}M \\
(n=55)\end{array}$ & SD & $\mathrm{M}_{\mathrm{Cl}}$ & & SD & $\mathrm{M}_{\mathrm{Cl}}$ & & & \\
\hline$H R$ & $1.74^{\mathrm{a}}$ & 0.49 & {$[1.65,1.83]$} & $3.72^{\mathrm{b}}$ & 0.50 & {$[3.57,3.86]$} & $2.46^{\mathrm{cd}}$ & 0.77 & {$[2.30,2.62]$} & $2.32^{\mathrm{dc}}$ & 0.51 & {$[2.20,2.44]$} \\
\hline AP & $1.77^{\mathrm{a}}$ & 0.54 & {$[1.65,1.89]$} & $3.20^{\mathrm{b}}$ & 1.00 & {$[3.01,3.39]$} & $2.75^{\mathrm{c}}$ & 1.00 & {$[2.54,2.96]$} & $3.69^{d}$ & 0.61 & {$[3.53,3.86]$} \\
\hline DPAL & $4.54^{\mathrm{a}, \mathrm{d}}$ & 0.47 & {$[4.45,4.64]$} & $4.14^{b}$ & 0.71 & {$[4.00,4.30]$} & $2.31^{\mathrm{c}}$ & 0.76 & {$[2.14,2.48]$} & $4.64^{\text {ad }}$ & 0.48 & {$[4.51,4.78]$} \\
\hline
\end{tabular}

Note. $\mathrm{TSCD}=\mathrm{SCHDE}$ Types of Self-Care dimensions; $\mathrm{HR}=$ Health representations; $\mathrm{AP}=$ Autonomous perspectives; $\mathrm{DAPL}=\mathrm{Demands}$ associated with personal life. $\mathrm{M}=$ Mean; $S D=$ Standard Deviation; $M_{C I}=$ Mean 95\% Confidence interval. Different letters identify significant differences of values in the cell to a significance of $p \leq$ .05 .

\subsection{Theoretical derivation}

The elderly included in cluster 1 , showed a predominance of the abandoned style, with weak health representations and the lowest value of the four clusters. This group corresponds to the elderly presenting a frail health condition, a reduced functional capacity to perform the ADLs and a low perception on autonomy associated to a high search for help to meet their needs.

The elderly in cluster 2 showed positive representations and an autonomous health perspective. They seem to accept the changes arising from old age and consider that the diseases and motor impairments do not hinder the experience of positive ageing. They show a reasonable functional capacity, autonomy and satisfaction with their health, thus identified in the responsible profile.

The elderly in cluster 3 seem to present mostly formally guided profile characteristics, with good health representations, but with low levels of autonomy (they differ from all groups). They are particularly demanding in what concerns personal life (they show the lowest value and differ significantly from all others) suggesting an acritical assumption of professional recommendations.

The elderly in cluster 4 present an independent profile, since they show high levels of autonomy and low health representations. This might explain their high demands on personal life, with similarities in this dimension when compared to cluster 1 . The perception of high autonomy may not be compatible with their own health condition, but rather to personality traits.

Hence, it is possible to conclude that, through cluster analysis, the factorial structure of these data is likely to replicate the theoretical model of Backman \& Hentinen (1999, 2001). The limitations that the elderly present in performing the ADLs, their perception of physical and cognitive impairments and the context in which they live might explain the results obtained.

Through the analysis of Table 3 it is possible to observe that Health shows a significantly higher mean for cluster 2 than for any other group, which may suggest the Responsible cluster or style. The latter is followed by cluster 3 and 4 , which do not show significant mean differences between them. Cluster 1 also differs from all others showing the lowest mean of Health representations. Cluster 4 has the significantly higher mean among all groups in the Autonomous perspective's dimension, suggesting the Independent cluster most predominant quality. It is followed by cluster 2, which reinforces cluster 2 as the Responsible type. The means for the Autonomous perspective's dimension, in descending order, are, respectively, the mean of cluster 3 and cluster 1 . These results strongly suggest the Abandoned type/ cluster as being cluster 1 , followed by the Formally guided cluster, with a slightly higher significant mean compared with the hypothetical Abandoned cluster. Finally, when analysing the Demands associated with the results for the personal life dimension, it is possible to con- clude that cluster 1 does not differ significantly from cluster 4 (although showing significant differences with the remaining clusters), which presents the highest scores, suggesting that the Abandoned cluster, as well as the Independent, have strong representations of difficult per-sonal lives. They are followed by cluster 2 (the Responsible), with a higher mean than expected, but considering the life experiences of this participants, mostly living in rural areas, this might not be a discrepancy. Finally, the Formally guided respondents had the lowest scores, which can be indicative of people used to having things done and decided by others, thus altering the perception of hard life in relation to others. Fig. 2 describes the results for SCHDE Types of Self-Care Clusters, considering the statistical results and the theoretical derivation. 


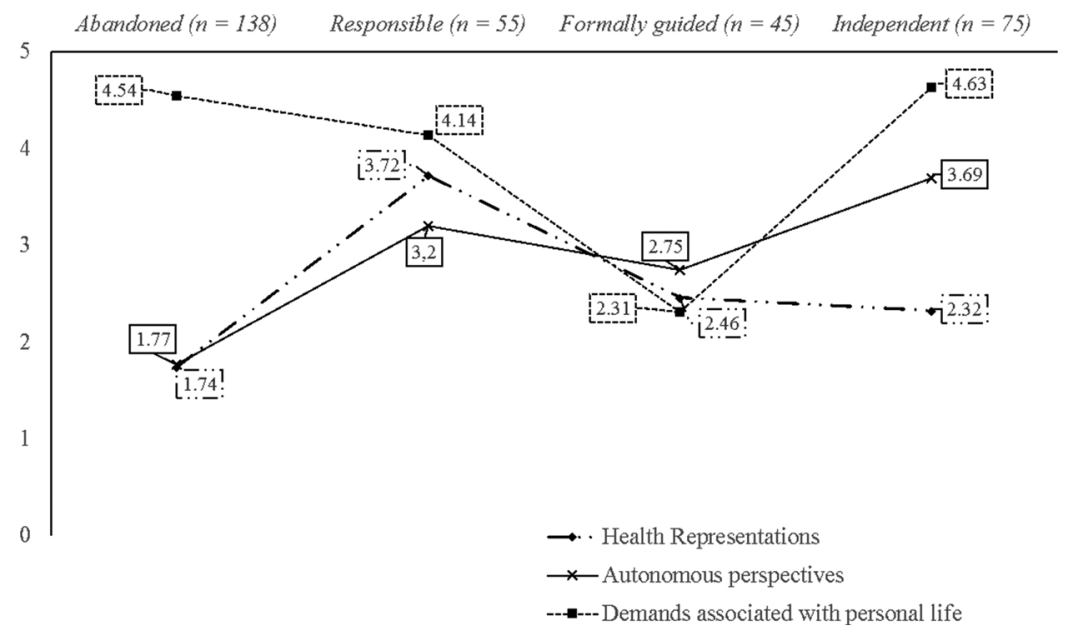

Fig. 2. Graphical representation of the final SCHDE Types of Self-Care Clusters. The effective value for each cluster is presented in brackets.

\section{Discussion}

The profile of the institutionalized elderly in elderly care centres is characterized by people with a very old age, mostly widowers, a low level of schooling, suffering from chronic diseases associated with the loss of independence and autonomy. The characteristics of the elderly in this study are in line with those described in the literature (Alencar, Bruck, Pereira, Câmara, \& Almeida, 2012; Peres, 2014; Pinto, 2016; Santos, 2016; Veríssimo, 2013). Thus, older age and the loss of functional capacity contribute to frailty and the loss of capacity to perform self-care activities (Zeleznik, 2007). The abandoned self-care profile shows greater incidence, which may be related to the context of the institutionalized elderly, to their age, low schooling levels and autonomy impairments, which influences the elderly person's decision to choose institutionalization (Zeleznik, 2007).

The studies conducted by Backman and Hentinen (2001) and Zeleznik (2007), identified the formally guided self-care as the most prevalent. In this study, the most prevalent profile was the abandoned self-care, followed by the independent self-care profile. These results might be explained by the fact that the participants were recruited from the institutional context (ECCs), rather than elderly living in home care contexts. For the majority, institutionalization was not their own decision, but a family decision, and this might likely contribute to the elderlies' resignation (abandoned profile) or the revolt and non-acceptance (independent profile).

Differences were found in the studied dimensions between the abandoned profile and formally guided, which can be explained by their specific characteristics. In the first profile, the participants need help in carrying out the daily activities and have little decision-making ability. In the second profile, participants follow recommendations without questioning. The philosophy of the institutions potentiates the withdrawal and accommodation to situations. In order to boost the processes of care delivery, they do not encourage the elderly to perform their activities independently, thus largely contributing to greater functional and intellectual impairments (Alencar et al., 2012).

Santos, Monteiro, Póvoa, Lima, and Silva (2014) stress that education in health, prevention and monitoring should take place since childhood until old age. This will likely help to minimize the occurrence of chronic-degenerative diseases and disabilities during the ageing process. They also state (ibid.) that the adoption of targeted health programs for a healthy ageing, represent an effective strategy for improving the quality of life and health of the elderly, thus ensuring autonomy and independence. The idea is not to undervalue the situations in which the elderly are already suffering from chronic diseases or experiencing disabilities, but to implement strategies to help overcome the difficulties. Silva and Santos (2010) argue that the elderly should be provided with opportunities to increase their own internal and external resources, thus facilitating self-care. For that, it is crucial to give the elderly the opportunity to learn how to be responsive, not only to health promotion, but also to changes caused by the disease and how to pre- vent deterioration of those conditions. In line with the authors, it has been argued that health care professionals, particularly nurses, must identify the needs and attitudes of older people in terms of self-care, in order to better adapt the care plans. Thus, they are able to leverage and promote the elderlies' competencies, suggesting the best tailored interventions that are responsive to the single needs of each patient.

\section{Conclusions}

Self-care means being able to take care of oneself. This is an individual lifestyle, shaped by values and beliefs specific to each culture and influenced by personal experiences, thus affecting personal perception on health and disease (Backman \& Hentinen, 1999; Zeleznik, 2007). It can also be influenced by age, the decline of functional capacity, therapeutic attitudes, personal experiences about the illness, social support, personal factors, quality of life, physical environment and the effectiveness of health professionals (Backman \& Hentinen, 2001; Zeleznik, 2007). Being able to provide an effective and tailored care, means that caregivers should not ignore these facts. According to Orem (2001) the action of self-care involves several areas, namely: the cognitive, which relates to the knowledge of the health condition and cognitive capacities necessary for the achievement of self-care; the physical, meaning the physical ability to perform self-care activities; the emotional or psychosocial, that relates to the attitude, the values, the will, the motivation and the perception of skills in performing self-care; and the behavioural, which consists of the skills needed to perform self- care behaviours.

The main purpose of government policies should be to promote the populations' literacy in health. This is the most effective strategy for 
disease prevention, particularly chronic diseases, to slow the decline of functional capacity, and prolong lifespan with quality of life. It is also important that health professionals, particularly nurses, do not focus interventions in elderly suffering from any disease, but rather target their interventions on promoting, maintaining and recovering health.

\subsection{Limitations of the study and future recommendations for future research}

A limitation of this study is the small geographic area involved. Thus, the generalizability of these results to the overall institutionalized Portuguese elderly population is subject to limitations. Therefore, these results need to be interpreted with caution. Hair et al. (2010) suggest that the minimum sample size for a factor analysis should be performed using a ratio of 5 observations by item, which we used in this study (42 items $\times 5=210$; our sample has 313 participants). Nevertheless, the authors also suggest that the optimal ratio should be of 10 observations per item, which can constitute a limitation. Notwithstanding, this study offers valuable insights for future research, in order to extend the sample to all regions of the country. Another limitation concerns the type of institutions participating in this study. Considering that only non-profit institutions were considered for this study, it would be interesting to extend the scope of the sample to for-profit institutions. This suggests that the typology of institutions may have different actions and philosophies and that a greater financial participation from its users could generate improved technical and physical conditions for the promotion of self-care of the institutionalized population.

\subsection{Implications for clinical practice}

These findings are an important contribution to the role of the caregivers and ECCs managers in identifying the elderly's frailties and in the planning and assessment of the care processes.

\section{Conflict of interests}

The authors declare no conflict of interests.

\section{Acknowledgements}

This article was supported by FEDER through the operation POCI-01-0145-FEDER-007746 funded by the Programa Operacional Competitividade e Internacionalização - COMPETE2020 and by National Funds through FCT - Fundação para a Ciência e a Tecnologia within CINTESIS, R\&D Unit (reference UID/IC/4255/2013).

\section{References}

Alencar, M. A., Bruck, N. N. S., Pereira, B. C., Câmara, T. M. M., \& Almeida, R. D. S. (2012). Perfil dos idosos residentes em uma instituição de longa permanência. Revista Brasileira de Geriatria e Gerontologia, 15(4).

Backman, K., \& Hentinen, M. (1999). Model for the self-care of home-dwelling elderly. Journal of Advanced Nursing, 30(3), 564-572.

Backman, K., \& Hentinen, M. (2001). Factors associated with the self-care of home-dwelling elderly. Scandinavian Journal of Caring Sciences, 15(3), $195-202$.

Clark, L. A., \& Watson, D. (1995). Constructing validity: Basic issues in objective scale development. Psychological Assessment, 7(3), 309-319.

David, M. I. D. (2015). Os perfis de autocuidado das pessoas com insuficiência renal crónica em hemodiálise e a sua perceção da qualidade de vida. Lisboa: Escola de Ciências e Tecnologia da Saúde, Universidade Lusófona de Humanidades e Tecnologia [Dissertação de mestrado não publicada].

Evaristo, A. M. A. (2015). O perfil de autocuidado dos clientes hemodializados: Influências no sucesso da gestão do regime terapêutico. Porto: Escola Superior de Enfermagem do Porto [Dissertação de mestrado não publicada].

FFMS (2017). Retrato de Portugal: indicadores 2017. Paris: PORDATA [Retrieved from https://www.pordata.pt/ebooks/PT2017v20170710/mobile/index.html\#p=1].

Field, A. (2009). Descobrindo a estatística usando SPSS (2a ed.). Porto Alegre: Artmed

Fortin, M.-F. (2003). Métodos de amostragem. In M.-F. Fortin (Ed.). O processo de investigação: da concepção à realização (pp. 201-214). (3ạ ed.). Loures: Lusociência.

George, D., \& Mallery, M. (2010). SPSS for Windows step by step: A simple guide and reference, 17.0 update (10th ed.). Boston: Pearson.

Hair, J. F., Black, W. C., Babin, B. J., \& Anderson, R. E. (2010). Multivariate data analysis (7th ed.). New Jersey: Prentice Hall.

Mota, A. M. A. (2011). O perfil de autocuidado dos clientes: exploração da sua influência no sucesso após transplante hepático. Porto: Escola Superior de Enfermagem do Porto [Dissertação de mestrado não publicada].

Orem, D. (2001). Nursing: Concepts of practice (6th ed.). St. Louis: Mosby.

Peres, M. O. (2014). Os idosos institucionalizados: estudo de algumas variáveis. Castelo Branco: Instituto Politécnico de Castelo Branco, Escola Superior de Saúde Dr. Lopes Dias [Dissertação de mestrado não publicada].

Petronilho, F. A. Z. (2012). Autocuidado: conceito central da enfermagem. Coimbra: Formasau.

Pinto, V. L. M. (2016). Caracterização do perfil cognitive de idosos portugueses analfabetos e institucionalizados: o contributo do Montreal Cognitive Assessment (MOCA). Lisboa: Universidade Lusófona de Humanidades e Tecnologias, Escola de Psicologia e Ciências da Vida [Dissertação de mestrado não publicada].

R Studio Team (2015). RStudio: Integrated development for R. RStudio. Boston, MA: RStudio Team Inc. http://www.rstudio.com/. 
Rasanen, P., Backman, K., \& Kyngas, H. (2007). Development of an instrument to test the middie-range theory for the self-care of home-dwelling elderly. Scandinavian Journal of Caring Sciences, 21(3), 397-405.

Rodrigues, L. (2011). O perfil de autocuidado como fator potencialmente condicionador das transições dos clientes: um estudo exploratório. Porto: Escola Superior de Enfermagem do Porto [Dissertação de mestrado não publicada].

Rosenberg, J. M., Schmidt, J. A., Beymer, P. N., \& Steingut, R. R. (2018). Interface to mclust to easily carry out Latent Profile Analysis. [Statistical software for R] https:// github.com/jrosen48/tidyLPA.

Santos, A. A. P., Monteiro, E. K. R., Póvoa, F. T. X., Lima, L. P. M., \& Silva, F. C. L. (2014). O papel do enfermeiro na promo'ço do envelhecimento saudãvel. Revista Espaço para a Saúde, 15(2), 21-28.

Santos, T. C. N. (2016). Associação entre estado nutricional e função cognitive em idosos residentes em lares. Lisboa: Universidade Nova de Lisboa, Escola Nacional de Saúde Pública [Dissertação de mestrado não publicada].

Sequeira, E. M. F. (2011). Os perfis de autocuidado dos clientes dependentes: estudo exploratório numa unidade de saúde familiar. Porto: Instituto de Ciências da Saúde da Universidade Católica Portuguesa [Dissertação de mestrado não publicada].

Silva, A. C. S., \& Santos, I. (2010). Promoção do autocuidado de idosos para o envelhecer saudável: aplicação da teoria de Nola Pender. Texto Contexto Enfermagem, $19(4)$, 745-753.

Tein, J. Y., Coxe, S., \& Cham, H. (2014). Statistical power to detect the correct number of classes in latent profile analysis. Structural Equation Modeling: A Multidisciplinary Journal, 20(4), 640-657.

Veríssimo, L. M. V. (2013). O autocuidado da pessoa institucionalizada: estudo exploratório em lares do grande Porto. Porto: Escola Superior de Enfermagem do Porto [Dissertação de mestrado não publicada].

Wichmam, F. M. A., Couto, A. N., Areosa, S. V. C., \& Menéndez Montañes, M. C. (2013). Grupos de convivñncia como suporte ao idoso na melhoria da sa'de. Revista Brasileira de Geriatria e Gerontologia, 16(4), 821-832.

Zeleznik, D. (2007). Self-care of home-dwelling eldernly people living in Slovenia. Eslovénia: Faculty of Medicine of University of Oulu, Oulu [Dissertation]. 